\title{
Cistanche deserticola decoction alleviates the testicular toxicity induced by hydroxyurea in male mice
}

\author{
Li Gu, Wen-Ting Xiong, Chao Wang, Hong-Xia Sun, Guo-Fu Li and Xin Liu
}

This study aimed to evaluate testicular toxicity induced by hydroxyurea (HU) and the possible counteracting effect of an aqueous extract of Cistanche deserticola (CD). HU is an antineoplastic drug that has potential reproductive toxicity, and Herba Cistanche has been used as a tonic for the reproductive system for thousands of years. Sixty mice were randomly divided into five groups. Except mice in normal group, the rest received $\mathrm{HU}\left(400 \mathrm{mg} \mathrm{kg}^{-1}\right.$ body weight) intragastrically. Meanwhile, mice in normal and $\mathrm{HU}$ control groups received purified water, and the rest received intragastrically three doses of $C D$ decoctions $\left(1.5,3.0\right.$ and $6.0 \mathrm{~g}$ crude drug kg $\mathrm{body}^{-1}$ weight, respectively) daily for 4 weeks. Severe testes lesions were observed, testes weight $(P<0.01)$ and serum luteinising hormone levels $(\boldsymbol{P}<0.01)$ were also decreased significantly, in the $\mathrm{HU}$ groups. Three doses of CD decoctions alleviated the spermatogenetic cell degeneration induced by $\mathrm{HU}$ and modulated the serum sex hormones levels to some extent.

Asian Journal of Andrology (2013) 15, 838-840; doi:10.1038/aja.2013.73; published online 1 July 2013

Keywords: Cistanche deserticola; hormones; hydroxyurea; seminiferous tubule

\section{INTRODUCTION}

Hydroxyurea (HU) is an antineoplastic drug that has cytotoxic effects on the rapidly proliferating $S$ phase of the cell cycle. However, at a dosage of more than $200 \mathrm{mg} \mathrm{kg}^{-1}$, $\mathrm{HU}$ results in testicular failure, reduced sperm quality and altered plasma hormone levels. ${ }^{1}$ The most sensitive indicators for detecting male reproductive toxicity are testicular weight and histopathological findings in the testes. The primary functions of testes are spermatogenesis and producing androgens, primarily testosterone, ${ }^{2}$ which is regulated by follicle-stimulating hormone (FSH) and luteinising hormone (LH) in the hypothalamuspituitary-gonad axis. ${ }^{3} \mathrm{HU}$ has been shown to suppress spermatogenesis and repress testosterone synthesis and release, ${ }^{1}$ which are likely responsible for male infertility. However, little attention has been focused on finding medications to alleviate testicular toxicity induced by HU.

Herba Cistanche, the stem of the Cistanche species, has been involved in herbal medicine as a tonic for thousands of years in some Asian countries. Among Cistanche species, Cistanche deserticola Y. C. MA (CD) has been indicated as the primary source material to tonify the kidney and invigorate the 'Yang' in traditional Chinese medicine theory, ${ }^{4}$ which is allegedly effective for reproduction, development and fertility function. Considering the benefits of $\mathrm{CD}$ on the reproductive system, in present study, the potential effects of CD supplementation against testicular toxicity induced by $\mathrm{HU}$ should be investigated.

\section{MATERIALS AND METHODS}

HU was purchased from QiLu Pharmaceutical Co., Ltd (Ji'nan, China). The dried stems of CD were purchased from Shenzhen
GURU Biology Co., Ltd (Shenzhen, China). CD samples were prepared as aqueous decoctions, and sixty male Kunming mice were randomised into five groups. Mice in the normal group were administered purified water intragastrically for 4 weeks daily, while the other mice received $\mathrm{HU}\left(400 \mathrm{mg} \mathrm{kg}^{-1}\right)$. Meanwhile, the CD-treated groups were administered intragastrically with $1.5 \mathrm{~g} \mathrm{~kg}^{-1}$ (low dose of $\mathrm{CD}$ decoction group, $\mathrm{LCD}+\mathrm{HU}$ ), $3.0 \mathrm{~g} \mathrm{~kg}^{-1}$ (median dose of $\mathrm{CD}$ decoction group, $\mathrm{MCD}+\mathrm{HU}$ ) and $6.0 \mathrm{~g} \mathrm{~kg}^{-1}$ (high dose of CD decoction group, $\mathrm{HCD}+\mathrm{HU}) \mathrm{CD}$ decoctions, respectively, while the normal and HU groups were administered water only. At the end of treatment, the testes were weighed, and a routine histological assessment was performed. Blood samples were obtained, and total serum hormones (testosterone, LH and FSH) concentrations were measured using commercial radioimmunoassay kits (Beijing North Institute of Biological Technology, Beijing, China).

\section{RESULTS}

The histological evaluation of testes from normal mice revealed a normal seminiferous epithelium with typical cell stages. The morphology of the spermatogonia, spermatocytes, round spermatids and sperms appeared normal (Figure 1a). However, severe lumen cavitation of the seminiferous tubule in the testes was observed in the HU group, with nearly all types of spermatogenetic cells degenerated. In some instances, the tubules were virtually empty, and some were collapsed (Figure 1b). However, when treated with $\mathrm{CD}$ decoctions, some spermatogonia and early spermatocytes (arrows) were observed in the seminiferous epithelium (Figure 1c-1e), although lumen cavitation of the seminiferous tubule was also exhibited in the testes. No apparent differences were found between the three CD-treated groups. 


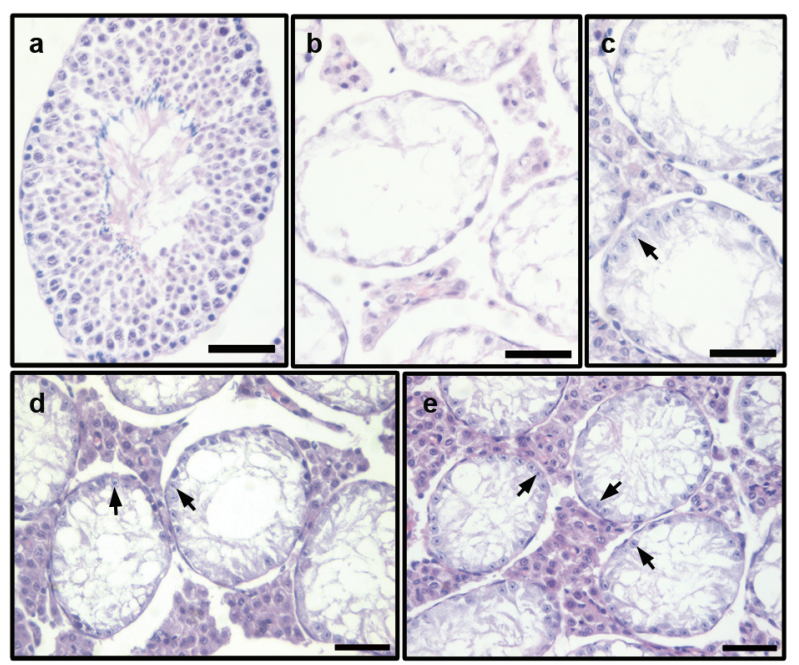

Figure 1 Morphological observation of the seminiferous tubule in testes of $\mathrm{HU}$-administered mice treated with of $1.5 \mathrm{~g} \mathrm{~kg}^{-1}$ (LCD+HU), $3.0 \mathrm{~g} \mathrm{~kg}^{-1}$ $(\mathrm{MCD}+\mathrm{HU})$ and $6.0 \mathrm{~g} \mathrm{~kg}^{-1}(\mathrm{HCD}+\mathrm{HU})$ Cistanche deserticola decoctions. (a) normal group, normal cell stage and all types of spermatogenetic cells were observed in the seminiferous epithelium; (b) HU group, severe lumen cavitation of seminiferous tubule in testes was observed, with almost all of the cells degenerated; (c) $\mathrm{LCD}+\mathrm{HU}$ group; (d) $\mathrm{MCD}+\mathrm{HU}$ group; (e) $\mathrm{HCD}+\mathrm{HU}$ group, lumen cavitation of the seminiferous tubule in the testes was observed, with some spermatogonia and early spermatocytes (arrows) present in the seminiferous epithelium. Scale bars $=50 \mu \mathrm{m}$. CD, Cistanche deserticola; HU, hydroxyurea.

At the end of 4-week experiments, the mean testes weight in the HU group was significantly less than that of the normal group $(P<0.01)$. In contrast with the HU controls, the testes weights increased approximately $25 \%$ in the LCD + HU group, $23 \%$ in the MCD + HU group and $28 \%$ in the $\mathrm{HCD}+\mathrm{HU}$ group. Furthermore, the average testosterone concentration in the HU mice was approximately $27 \%$ lower than their normal counterparts. However, the testosterone concentration tended to be increased by approximately $25 \%$ and $22 \%$ in the $\mathrm{HCD}+\mathrm{HU}$ and MCD $+\mathrm{HU}$ groups, respectively, compared with the $\mathrm{HU}$ control. In addition, the mean serum LH levels in HU mice were reduced by $65 \%(P<0.01)$ compared with normal control. However, CD decoctions increased serum LH levels approximately $28 \%$ in the $\mathrm{HCD}+\mathrm{HU}$ group, $26 \%$ in the MCD $+\mathrm{HU}$ group and $30 \%$ in the LCD $+\mathrm{HU}$ group. No significant differences were observed between the groups regarding FSH concentrations (Table 1).

\section{DISCUSSION}

Our results demonstrated that excess HU resulted in serious testicular lesions and decreased serum testosterone and LH levels. However, $\mathrm{CD}$ decoctions counteracted the hazardous effects of $\mathrm{HU}$ on the seminiferous tubules of the testes and modulated hormones levels to some extent.

One of the primary functions of testes is sperm production. Several retrospective studies reported abnormal sperm parameters during and after treatment with $\mathrm{HU}{ }^{5}$ Spermatogenesis depends on the normal number and morphology of spermatogonia, spermatocytes and round spermatids. HU induces testicular germ cell apoptosis in a time- and stage-specific pattern, followed successively by spermatogonia, spermatocyte and spermatid because spermatogonia are sensitive to chemotherapeutic drugs. ${ }^{6}$ When administered with HU continuously, no interactions between spermatogenetic cells and Sertoli cells were observed, and the sperm, round spermatids, spermatocytes and spermatogonia came off successively in addition to the testicular defect; thus, the atrophied seminiferous tubules, which contained large vacuoles and few cells, had considerably smaller diameters compared with the normal tubules in $\mathrm{HU}$-administered mice.

We also observed that the seminiferous tubules were virtually empty and that the testicular weights were decreased under HU administration. However, CD remitted the testes shrink by $20 \%-70 \%$ compared with the HU controls, with some spermatogenetic cells still present in the seminiferous epithelium. The inhibition of DNA synthesis is involved in mediating the toxicity of $\mathrm{HU}^{7}$ which is related to an involution of spermatogenetic cells. Interestingly, Liu et al. ${ }^{8}$ found that the DNA synthesis of the liver and spleen of mice damaged by $\mathrm{HU}$ was recovered by CD decoction. The resumption of spermatogenesis was thus probably due to the recovery of DNA synthesis in testes by $\mathrm{CD}$.

In males, androgen plays a key role in the development of male reproductive tissues. ${ }^{9}$ We found that $\mathrm{CD}$ decoction tended to increase serum testosterone content, likely due to its androgen-like effect. ${ }^{10-12}$ However, supraphysiological doses of testosterone and its derivatives are known to suppress spermatogenesis. ${ }^{13}$ Toxicology research has shown that the serum testosterone levels decreased to approximately 5.0-10.0 g crude drug $\mathrm{kg}^{-1}$ body weight of CD decoction in normal mice. ${ }^{14}$ It is possible that the suppression effect of $\mathrm{CD}$ as an ectogenic androgen-like agent made the dose-dependent effect of the three doses of $\mathrm{CD}$ decoctions against testicular injury more difficult to detect. Therefore, dosages should be kept within safe limits.

In males, testosterone is synthesised and secreted by Leydig cells of the testes and is regulated by $\mathrm{LH}$ and $\mathrm{FSH}^{15}$ The regulation of testosterone synthesis appears to be the only indispensable function of LH within the adult testes, ${ }^{3,15}$ and the feedback control of testosterone by LH is consistent. However, the feedback control of testosterone by FSH is relatively complex. ${ }^{16}$ In the current study, HU affected the LH endocrine function more than FSH function in male mice, while the effects of CD on LH and FSH levels were not easily detected.

In conclusion, $\mathrm{HU}$ caused testicular lesions at a dosage of $400 \mathrm{mg} \mathrm{kg}{ }^{-1}$. CD decoctions alleviated the spermatogenetic cell

Table 1 Testes weights and serum hormones levels in mice at the end of the 4-week experiment

\begin{tabular}{|c|c|c|c|c|c|}
\hline & Normal & $H U^{\mathrm{a}}$ & $L C D+H U\left(1.5 \mathrm{~g} \mathrm{~kg}^{-1}\right)$ & $M C D+H U\left(3.0 \mathrm{~g} \mathrm{~kg}^{-1}\right)$ & $H C D+H U\left(6.0 \mathrm{~g} \mathrm{~kg}^{-1}\right)$ \\
\hline Testes weights (mg) & $208.9 \pm 27.7$ & $46.3 \pm 7.7^{b}$ & $58.0 \pm 5.6$ & $57.1 \pm 11.1$ & $59.4 \pm 9.9$ \\
\hline $\mathrm{T}\left(\mathrm{ng} \mathrm{ml^{-1 }}\right)$ & $0.49 \pm 0.08$ & $0.36 \pm 0.02$ & $0.34 \pm 0.01$ & $0.44 \pm 0.01$ & $0.45 \pm 0.05$ \\
\hline $\mathrm{LH}\left(\mathrm{mlU} \mathrm{ml}^{-1}\right)$ & $11.68 \pm 0.77$ & $4.11 \pm 0.51^{\mathrm{b}}$ & $5.33 \pm 0.81$ & $5.16 \pm 0.53$ & $5.25 \pm 0.50$ \\
\hline
\end{tabular}

Abbreviations: $\mathrm{CD}$, Cistanche deserticola; FSH, follicle-stimulating hormone; $\mathrm{HU}, \mathrm{HU}$ control group; $\mathrm{LCD}+\mathrm{HU}, \mathrm{MCD}+\mathrm{HU}$, and $\mathrm{HCD}+\mathrm{HU}$, low, median and high doses of Cistanche deserticola decoctions used to treat the HU-administered mice group; LH, luteinising hormone; T, testosterone.

${ }^{a}$ Data are expressed as mean \pm s.d. $(n=12)$.

${ }^{\mathrm{b}} P<0.01$ compared with normal control. 
degeneration induced by $\mathrm{HU}$; this effect is related to its ectogenic androgen-like effect. However, our report opens the debate on whether CD is beneficial for sperm beyond one sperm cycle through the recovery of DNA synthesis in testes cells.

\section{AUTHOR CONTRIBUTIONS}

LG and XL conceived the study and participated in its design. WTX and CW performed the animal experiments and histological assessment. LG and HXS participated in the hormone assessment. LG drafted the manuscript. GFL performed the statistical analysis and helped revise the manuscript. All authors read and approved the final manuscript.

\section{COMPETING FINANCIAL INTERESTS}

The authors have no competing financial interests.

\section{ACKNOWLEDGMENTS}

This work was supported by a grant from the Science and Technology Support Project in Nanshan Region of Shenzhen (China) (No.2009058).

1 Jones KM, Niaz MS, Brooks CM, Roberson SI, Aguinaga MP et al. Adverse effects of a clinically relevant dose of hydroxyurea used for the treatment of Sickle cell disease on male fertility endpoints. Int J Environ Res Public Health 2009; 6: 1124-44.

2 Pereira ML, Santos TM, das Neves RP, Costa FG, de Jesus JP. Cr(V) involvement in the toxicity pathway of testicular damage. Asian J Androl 2002; 4: 153-5.

3 Robert WH, Robert EB. Hormonal regulation of spermatogenesis. Int J Androl 2004; 27: 335-42.
4 Jiang Y, Tu PF. Analysis of chemical constituents in Cistanchespecies. J Chromatogr A 2009; 1216: 1970-9.

5 Strouse JJ, Heeney MM. Hydroxyurea for the treatment of sickle cell disease: efficacy, barriers, toxicity, and management in children. Pediatr Blood Cancer 2012; 59: 36571.

6 Shin JH, Mori C, Shiota K. Involvement of germ cell apoptosis in the induction of testicular toxicity following hydroxyurea treatment. Toxicol Appl Pharma 1999; 155: 139-49.

7 Larouche G, Hales BF. The impact of human superoxide dismutase 1 expression in a mouse model on the embryotoxicity of hydroxyurea. Birth Defects Res A Clin Mol Teratol 2009; 85: 800-7.

8 Liu FC, Ding GX, Li JX. The effects of Epimedium sagittatum and Cistanche deserticola on DNA synthesis in "Yang-insufficiency" animal model induced by hydroxyurea. Chin J Int Tradit West Med 1984; 8: 488-91.

9 Mooradian AD, Morley JE, Korenman SG. Biological actions of androgens. Endocr Rev 1987; 8: 1-28.

10 He W, Zong GZ, Wu GL, Chen MH. Exploration for active ingredients of Cistanche on androgen like effect. Chin J Chin Mater Med 1996; 9: 564-5.

11 Zhang Y, Wu H, Wang SN, Zheng HC. Comparison on the kidney nourisking and "Yang" strengtkening functions of three different species of herba Cistancbe. Chin J Chin Mater Med 1994; 3: 169-71.

12 Zong GZ, He W, Wu GL, Chen MH, Shen X et al. Comparisons between Cistanche deserticola Y. C. Ma and C. tubulosa (Schenk) R. wight on some pharmacological actions. Chin J Chin Mater Med 1996; 7: 436-7.

13 Purohit SB, Saxena D, Laloraya M, Kumar GP. Altered molecular dynamics and antioxidant status in the spermatozoa in testosterone-induced oligospermia in mouse. Molecul Reprod Dev 2000; 55: 316-25.

14 Kim SW, Yoo SH, Lee HJ, Kim K, Kim do R et al. Cistanches herba induces testes cytotoxicity in male mice. Bull Environ Contam Toxicol 2012; 88: 112-7.

15 Nieschlag E, Simoni M, Gromoll J, Weinbauer GF. Role of FSH in the regulation of spermatogenesis: clinical aspects. Clin Endocrinol 1999; 51: 139-46.

16 Hellqvist A, Schmitz M, Borg B. Effects of castration and androgen-treatment on the expression of $\mathrm{FSH}-\beta$ and $\mathrm{LH}-\beta$ in the three-spine stickleback, gasterosteus aculeatus-feedback differences mediating the photoperiodic maturation response? Gen Comp Endocr 2008; 158: 178-82. 